\title{
Contractualism and the Counter-Culture Challenge
}

\author{
Jussi Suikkanen
}

Final Author Copy; To be published in Oxford Studies in Normative Ethics 7 (2017).

\section{Introduction}

Many of us rely on simple 'what if everyone did it?' thinking in ethical deliberation (Hooker 2000: 5). We think, for example, that it is wrong to jump a queue because not everyone could do so (Parfit 2011: vol. 1, 302305). The idea here is that there is something fundamentally wrong about making an exception of yourself. Thinking in this simple way is, of course, an imperfect guide to right and wrong: it is morally permissible to dine at a friend's place at $7 \mathrm{pm}$ on Mondays even if not everyone could do so (Hooker 2000: 5; Bittner 1974: 487). Yet, there still is something appealing about thinking about morality in this simple way.

A number of ethical theories attempt to develop the previous type of everyday ethical thinking into something more systematic and defensible. Instead of considering what would happen if everyone acted in one way, they tend to focus on the consequences of everyone accepting the same moral code (that is, the same set of moral principles). ${ }^{1}$ This solves the previous problem. Even if everyone endorses the principle that it is permissible to

\footnotetext{
${ }^{1}$ The rules that constitute a moral code need not be simple, absolute, and exceptionless principles that can be stated simply in words (principles such as 'Do not kill!'). We can think of a moral code as a complex moral sensitivity that can be internalized - that is, as "a moral conscience with a certain shape" (Hooker 2000: 91). In this way, the relevant sensitivity determines when a given rule applies, what exceptions it admits, and what strength it has in conflict cases (Hooker 2000: 90-91; Scanlon 1998: 197-202). The acceptance of the rule that governs killing, for example, includes the disposition for being motivated not to kill in a vast number of situations (but perhaps not in all), a disposition to have reactive attitudes such as blame towards those who kill in most contexts, and so on.
} 
dine at a friend's place at 7pm on Mondays, not everyone will want to do so and therefore everyone accepting this principle will not have any awkward consequences (Hooker 2000: 5).

These ethical theories must then decide how we should evaluate the consequences of everyone accepting the same moral code. We can first image a set of possible worlds exactly like our own world except that in each one a different moral code has been internalized by everyone. That is, we can pair each moral code we could internalize with a world in which that code has been internalized by everyone.

Different ethical theories then compare the worlds in which different moral codes have been internalized in different ways. In these worlds, because different moral codes have been internalized, individuals come to live different kind of lives (Scanlon 1998: 202-206). A basic rule-utilitarian theory would first pick out the world that contains the highest total amount of well-being (Brandt 1959: 413-422; Frankena 1973: 39-43). It would then state that the moral code internalized in that world determines what is right and wrong. On this view, an action is right if and only if it is authorized by the moral code the universal acceptance of which produces the highest total amount of well-being, and wrong otherwise. In the same way, more sophisticated rule-consequentialist views pick out the world and the moral code that maximize the amount of good understood in some more complicated way. ${ }^{2}$

A shared feature of all rule-consequentialist views is that, when they compare the relevant worlds, they interpersonally aggregate together how good the lives of different people are in them. These views are then interested in the highest sum or the highest average of well-being and/or some other values found from these worlds. Each individual's well-being and possibly other personal values are merely considered to be elements of the compared sums or averages. In contrast, contractualist

\footnotetext{
2 The axiology of the rule-consequentialist can include other intrinsic values than well-being and also give priority to the position of the worst-off (Hooker 2000: secs. 2.2 and 2.8).
} 
theories tend to compare the relevant worlds and their moral codes without this type of interpersonal aggregation. $^{3}$

Here is a sketch of how the non-aggregative contractualist comparisons of the relevant worlds and codes work. From each world, we first find the individual whose life has been burdened the most as the result of the moral code that has been internalized by everyone in that world (Scanlon 1998: 195 and 208). This is the person whose life is the least choice-worthy in that world because of the generic and concrete burdens such as bodily injuries, inability to rely on the assurances of others, and not having control over what happens to her body (Scanlon 1998: 204).

We can then stipulate that this person has the most serious personal objection to the moral code she lives under on the basis of the previous personal burdens. After this, we can compare the most serious personal objections of each world against one another. Contractualists call the moral code to which there is the least serious of these personal objections the moral code which no one could reasonably reject (Scanlon 1998: 195). ${ }^{4}$ This is because all other moral codes burden individuals in more serious ways than this code. The individuals who would have to bear those unnecessary serious burdens could reasonably reject the code that would cause them those burdens. The claim then is that an action is right in our world if and only if it is authorized by the moral code which no one could reasonably reject, and wrong otherwise (Scanlon 1998: 4 and 153).

\footnotetext{
3 See Scanlon (1998: 229-241), Parfit (2003: 369) and Ridge (2001).

${ }^{4}$ If there are many codes to which the most serious personal objections are equally least serious, we first consider which of these worlds contains the fewest of these objections (Scanlon 1998: 232). If there are many worlds that contain an equal number of the relevant most serious objections, we compare the second most serious objections in the same way. If these are tied in both seriousness and number, we keep moving to the next levels until we find a unique code. If there are many codes that contain an equal number of equally serious objections at each level in the previous comparisons, we choose the code closest to the conventional morality (Hooker 2000: 114-117).
} 
Since the publication of T.M. Scanlon's What We Owe to Each Other, the critics of contractualism have made many powerful objections to contractualism. It has been argued that (i) contractualism is merely a redundant spare wheel in ethical theorising, that (ii) it leads to implausible conclusions about how groups should be treated, that (iii) it is too demanding, and that (iv) it fails to account for our moral obligations that govern how we are to treat animals and cognitively impaired human beings. ${ }^{5}$ Instead of these old objections, I want to explore a new one. ${ }^{6}$ This challenge was first formulated by Holly Smith as an objection to rule-consequentialism in (Smith 2010: 426432). I call it the counter-culture challenge.

In order to understand this challenge, we must first briefly consider at what level of social acceptance the different moral codes should be compared. ${ }^{7}$ Section 2 will explain the contractualist responses to this question and how they directly lead to the counter-culture challenge. This challenge threatens to undermine contractualism in a fundamental way because, if it is successful, the contractualist framework will be unable to pick out a nonarbitrary moral code, which would be essential for the project of explaining which actions are right and wrong

\footnotetext{
${ }^{5}$ For an overview, see Southwood (2003: sec. 3). For discussions of (i), see Thomson (1990: 30, n. 19 and 188); Blackburn (1999); and Pettit (2000: 162). For discussions of (ii), see Hooker (2003), Kumar (2001), Norcross (2002), Otsuka (2000), Parfit (2003), Raz (2003) and Reibetanz (1998). For (iii), see Ashford (2003). Finally, for (iv), see Hooker (2000: 66-70), Carruthers (1992: ch. 4), and Phillips (1998).

${ }^{6}$ Scanlon addressed many of these objections in What We Owe to Each Other (Scanlon 1998). See pages 194 and 215-218 (objection (i)), 229241 (objection (ii)), 224-225 (objection (iii)), and 177-187 (objection (iv)). See also Scanlon (2000, 2002a, 2002b, 2003a and 2003b). Contractualism has in addition been defended, for example, by Hirose (2001), Kumar (2000), Ridge (2001), Southwood (2010), Stratton-Lake (2003), and Suikkanen (2004, 2005, and 2014).

7 This question has been debated in the rule-consequentialist literature (Brandt 1959, sec. 8, Brandt 1992: 149-154, Hooker 2000: sec. 3.3, Hooker and Fletcher 2008, Regan 1980, Ridge 2006 and 2009, and Smith (2010). Parfit (2011: vol. 1, 312-320) discusses this objection in the context of Kant's Law of Nature Formula and ruleconsequentialism. Contractualists have not yet discussed this problem with the exception of Suikkanen (2014).
} 
and why. The final section 3 then introduces and critically evaluates different responses to the counter-culture challenge. I will argue that there is a version of contractualism, Real World Contractualism, which can successfully deal with the objection.

\section{Levels of Social Acceptance and the Counter- Culture Challenge}

When I introduced contractualism, I stipulated that everyone in the considered worlds has internalized the compared moral codes. That is, if the moral principle 'Do not lie!' belongs to the moral code that has been internalized in a given world, then absolutely everyone in that world has internalized this principle. As explained in footnote 1, this does not entail that no one lies in this world. It means only that everyone thinks in this world that lying is wrong, everyone is inclined not to lie, and everyone is disposed to blame people who lie and to feel guilty if they lie themselves. I hence assumed that the moral codes are compared at $100 \%$ level of social acceptance but not at $100 \%$ level of compliance.

Comparing moral codes in this way is problematic for two reasons. Firstly, there are some principles that have very good consequences for individuals at 100\% level of acceptance even if they are catastrophic in other circumstances (Parfit 2011: vol. 1, 315-316). For example, the rule "Do not be violent unless some other people endorse violent rules, in which case kill as many people as you can!" is benign in a world where everyone accepts non-violent rules but it would have horrific consequences in the real world where some people accept violencepermitting principles.

The second problem is that, as a consequence of comparing codes at $100 \%$ level of acceptance, contractualism is unable to account for many intuitively compelling moral requirements which we have in the nonideal circumstances (Hooker 2000: 82). For example, there are a number of moral requirements to do with how we are to treat people who have not internalized any moral principles. Intuitively we ought to help them to internalize the moral principles to which we are all committed. Call 
these the duties of moral inculcation. There are also requirements to do with how we are to treat people who accept different moral principles than us. If someone disagrees with you about the moral status of cloning, you are not allowed to force that person to change her view by deception or coercion. Call this type of requirements the duties that govern moral disagreements.

If we compared different moral codes at the $100 \%$ level of social acceptance, we could not explain the existence of the previous duties. In the compared worlds, there would be no need for moral inculcation and there would be no moral disagreements. Everyone has already internalized the same moral codes. Because of this, there are no reasons to add to the compared codes any principles that govern moral inculcation and dealing with moral disagreements. Such principles would only make the relevant codes more complicated and more difficult to internalize which would unnecessarily burden everyone (Hooker 2000: 96). This is why the moral code that could not be reasonably rejected in the universal acceptance comparisons would not contain any duties of moral inculcation or ones governing moral disagreements. As a consequence, universal acceptance contractualism could not explain why we have these duties in the real world.

Contractualists should hence compare the relevant moral codes at a lower level of social acceptance. They could, for example, just stipulate a certain rate of imperfect acceptance. They could, thus, assume that an overwhelming majority of $90 \%$ accepts the relevant codes in the compared worlds (Hooker 2000: 84). These worlds would then contain some people who are violent, some people who are in the need of moral inculcation, and also some moral disagreements. We could then consider what consequences different principles that govern the use of violence, moral inculcation, and moral disagreements would have for the lives of the individuals in these worlds.

The principle "Do not be violent unless some other people endorse violent moral rules, in which case kill as many people as you can!" would have disastrous consequences in these $90 \%$ worlds. Following it would lead to a vast 
number of unnecessary deaths and for this reason this principle could surely be reasonably rejected.

Consider then those worlds in which the 90\% majority believes that it is wrong to allow human organs to be sold. Some of the remaining $10 \%$ will disagree with this moral belief, and so these $90 \%$ worlds will also contain moral disagreements. In some of these worlds, the $90 \%$ majority thinks that it is permissible to solve moral disagreements by deception, blackmail, and coercion whereas in others the vast majority believes that only rational persuasion is permissible. This difference in the majorities' beliefs will then affect what kind of lives people come to live in the compared worlds. It might well be that solving disagreements by deception, blackmail, and coercion leads to unnecessary burdens and for this reason moral codes that permit people to behave in these ways in disagreements can be reasonably rejected. This illustrates how the contractualists can use the 90\% level of acceptance to give an account of our duties that govern moral inculcation and moral disagreements.

Contractualists have also other alternatives. Following Derek Parfit, they could compare the consequences of the internalization of different moral codes at every level of acceptance (Parfit 2011: vol. 1, 317). They could then hope that there is a moral code that is the least burdensome for individuals at every level of acceptance (that is, at $100 \%$ level of acceptance, at $99 \%$ level of acceptance, ..., and at $1 \%$ level of acceptance). Or, following Michael Ridge's variable rate rule-utilitarianism, contractualists could consider how burdensome different codes are for individuals on average when we consider their consequences for individuals at every level of social acceptance (Ridge 2006 and 2009).

Finally, contractualists could also think that each code generates its own equilibrium level of social acceptance depending on the strength of its duties of moral inculcation. For example, codes that contain demanding inculcation elements will create high levels of social acceptance whereas codes with more laissez-faire inculcation elements will be able to sustain only low levels of social acceptance. We could then compare how 
burdensome these codes are for individuals at their equilibrium levels (Smith 2010: sec. 2; Suikkanen 2014).

I will be neutral between these answers to the question of at what level of social acceptance moral codes should be compared. I will assume that contractualists need to compare moral codes at some level of social acceptance $\mathrm{n} \%$ where $0<\mathrm{n}<100$. Here $\mathrm{n}$ might be a set level, a different level for each code depending on what kind inculcation element the code contains, or a short-hand for a whole set of levels of social acceptance at which the codes are to be compared. I want to focus, instead, on a new challenge which we face when we compare moral codes at a lower than $100 \%$ level of acceptance.

When we compare moral codes at a lower than 100\% level of acceptance, we will need to answer two questions. The first easy question is: who are the individuals who have not internalized the relevant moral codes in the compared worlds? Answering this question is important because it could well be that a given code has one set of consequences if one group of people internalizes it and another set of consequences if a different group does so.

We can begin from the idea that it is possible to rank people in terms of how naturally they internalize moral codes. This ability is based on the individuals' genes which are responsible for their innate cognitive and emotional capabilities. The idea then is that the noninternalizers in the compared worlds are those individuals who share the innate features of the group of people who are the hardest to inculcate in the real world.

The more difficult question is the counter-culture challenge itself (Smith 2010: 426-432). When we compare different moral codes at $\mathrm{n} \%$ of social acceptance, the people who have not internalized the same moral code as the majority must have some beliefs, cares and concerns, values, emotions, and motivational and behavioural dispositions. Let us call these individuals code-rejectors and the previous sets of attitudes and dispositions countercultures.

The crux of the challenge is that the counter-cultures internalized by the code-rejectors will influence what 
consequences the compared moral codes will have for the lives of different individuals, because different countercultures make the code-rejectors behave in different ways in reaction to other people. The final part of the objection is that there is no non-arbitrary way of choosing which counter-culture has been adopted in the compared worlds by the code-rejectors (Smith 2010: 428). As a consequence, the comparisons of the moral codes in the contractualist framework will be arbitrary and for this reason contractualism will be unable to explain which actions are right and wrong and why (Smith 2010: 432). This objection seems to undermine the foundations of the whole contractualist project.

One part of this challenge needs to be explained more. We can ask: how could the adopted counter-cultures affect what consequences different codes have for the lives of the individuals in the compared worlds? Let us consider a simple example.

Consider two counter-cultures: Lazies and Crazies. ${ }^{8}$ Lazies fail to count as people who have internalized a moral code because they never want to do anything. They have no desire to help other people, keep promises, tell the truth, pay taxes, and so on. Crazies, in contrast, want to cause as much chaos as possible. They are strongly disposed to kill, rape, abuse, lie, cheat, and steal. In this situation, it is easy to see that moral codes can have very different consequence depending on whether the code-rejectors are Lazies or Crazies.

Take the moral principle according which it is permissible to carry, buy, and sell fire-arms. In the Lazy counterculture worlds, the adoption of this principle will not have any harmful consequences. The Lazies are just too anaemic to use the available fire-arms to harm anyone. Thus, if we consider the previous principle in the Lazy worlds, this principle could probably not be reasonably rejected by anyone. Things look very different if we consider this same principle in the Crazy worlds. In them, the Crazies are inclined to shoot people if they have an

\footnotetext{
${ }^{8}$ I borrow the names from Van Parijs (1991: 105) even if my characters are different from his.
} 
access to fire-arms and so, in this context, the relevant moral permission would have disastrous consequences. It would result in some individuals getting shot and therefore in the Crazy worlds this principle could probably be reasonably rejected.

This means that whichever counter-culture we stipulate to have been internalized by the code-rejectors now determines whether or not it is morally permissible to carry, buy, and sell fire-arms. The crux of the counterculture challenge is that there is no non-arbitrary way of specifying which counter-culture we should use in this type of comparisons. If that is true, then contractualism is unable to lead to non-arbitrary conclusions about right and wrong.

\section{Contractualist Responses to the Counter-Culture Challenge}

\subsection{The Reflective Equilibrium Response}

The first contractualist response to the counter-culture challenge relies on the reflective equilibrium method. Its basic idea is that the ultimate aim of ethical theorizing is to formulate a theory which best coheres with our carefully considered moral convictions about individual cases. ${ }^{9}$ In the case of contractualism, this means that our task is to specify a contractualist framework for comparing moral codes such that its output code will cohere with our moral convictions. It is then thought that the resulting fit between our carefully considered moral convictions and the moral theory can both (i) justify believing that the moral theory is correct and (ii) vindicate our moral convictions from a more theoretical perspective.

According to the reflective equilibrium response, in the contractualist comparisons of codes, we are therefore to use the counter-culture - whichever it is - which will ensure that the output moral code will match our carefully considered moral convictions. Here we explicitly use our pre-theoretical moral convictions to choose a suitable

\footnotetext{
${ }^{9}$ See Daniels (1979), Hooker (2000: 9-16), and Rawls (1971: 19-21 and 46-51). For objections, see Brandt (1979: 21-22) and Hare (1973).
} 
counter-culture for the contractualist comparisons of moral codes. As a consequence, the counter-culture used in the contractualist framework will not be arbitrary because the counter-culture is chosen specifically for the reason that it enables us to reach a reflective equilibrium between the moral code picked out by the contractualist framework and our moral convictions.

This solution has a significant cost: it leads back to the redundancy objection (footnote 5, objection (i)). Contractualists aim to provide an illuminating explanation of which actions are right and wrong and why (Scanlon 1998: 10-13; Southwood 2010: 7-12). In order to achieve this aim, contractualism should be able to justify our carefully considered pre-theoretical moral convictions from a perspective that does not directly depend on those convictions themselves. Contractualists are able to satisfy this constraint only if they do not directly rely on the carefully considered moral convictions when they formulate and apply the reasonable rejection test (Hooker 2003: 57-62; Parfit 2003: 370; Parfit 2011: vol. 1: §54).

If contractualists use the reflective equilibrium response to the counter-culture challenge, they are no longer able to provide the required kind of independent explanation of rightness and wrongness. In giving this response, contractualists would rely on their moral convictions within the formulation of the reasonable rejectability test. ${ }^{10}$ In this situation, the contractualist framework and its output moral code would become a spare wheel that does no work: the theory would rely too much on our pretheoretical moral convictions to play a useful role in explaining what is right and wrong. Contractualism would lack both (i) the ability to offer a critical perspective for evaluating our carefully considered moral convictions and (ii) the ability to justify our moral convictions from a more theoretical independent perspective. For this reason,

\footnotetext{
10 This problem resembles an objection to Rawls's theory of justify. It is argued that Rawls selects the features of the Original Position on the basis of pre-theoretical moral assumptions about what is just that have not yet been vindicated by that test (Kymlicka 1991: 193).
} 
if contractualists have any critical and explanatory ambitions, they need a better response.

\subsection{The Human Nature Response}

I assumed earlier that our genes determine how easily we internalize moral codes. This idea could also be used for responding to the counter-culture challenge. It could be claimed that there is a genetically determined 'human nature', which is an outcome of an evolutionary struggle for survival. This human nature consists of a set of beliefs, cares and concerns, values, emotions, and motivational and behavioural dispositions which we human beings have innately due to our evolved biological nature.

It could then be suggested that morality is a cultural construct: a system of new beliefs, cares and concerns, values, emotions, and motivational and behavioural dispositions that is a human invention and culturally transmitted from one generation to the next. Its function could be argued to be to reign in our uninhibited, selfish, and often destructive natural inclinations so that we all will be better off as a result (Alexander 1987; Dawkins 1976). The response to the counter-culture challenge would then be that the people who have not internalized the relevant moral codes in the compared worlds are unaffected by any culture. Their genetically fixed human nature determines how they think and what they do. We then compare the consequences of different moral codes in worlds in which the code-rejectors act purely on the basis of their biological human nature.

This response has several problems. Firstly, we should be suspicious of the idea that there is a robust genetically fixed human nature which determines how individuals think and behave when they are unaffected by culture. There are good reasons to doubt whether biological and genetic determinism is true (James 2011: 5). Some believe that evolution itself has given us a general ability to decide whether we are to act on the inclinations and preferences which our genes and cultural environment provide for us (de Lazari-Radek \& Singer 2014: 182-183). If this were correct, there would be no biological human 
nature which determined how people behave when they are not influenced by culture.

We should also be sceptical about whether our biological human nature is genuinely uninhibited, selfish, and destructive. Perhaps there is instead a way of reconciling our biological nature and being moral. This would mean that we have the beliefs, cares and concerns, values, emotions, and motivational and behavioural dispositions that are considered to be broadly speaking moral because having an altruistic nature was an evolutionary advantage. ${ }^{11}$ It sustained co-operation which helped our kin and genetic material to survive.

In this situation, the human nature response would lead to unintuitive conclusions about what is right and wrong. If we accept that the biological human nature is fundamentally good, then the code-rejectors would still be pretty decent people morally speaking. In fact, their views and behaviour would not differ much from the views and behaviour of the vast majorities who have internalized the moral codes of the compared worlds. As a consequence, the least burdensome code would need to contain only weak moral principles governing moral inculcation and moral disagreements.

Things get even worse for this response. In addition to the potentially biologically determined types of wrong-doing, there are also invented types. Consider female genital mutilation. The willingness to take part in this practice cannot have an evolutionary origin given that most human groups have never participated in this practice.

Let us then compare different moral principles in worlds in which the counter-culture is determined solely by the biological human nature of the code-rejectors. In this situation, in the world in which the least burdensome code has been accepted, the $\mathrm{n} \%$ majority of people are against female genital mutilation. Codes which endorse this

11 Even if we probably did not evolve to internalize a universal principle of benevolence, there is good empirical evidence that we did evolve to be altruistic towards some limited group around us (Sober \& Sloan Wilson 1998). 
practice cause unnecessary suffering to women and for this reason such codes can be reasonably rejected. However, in the worlds we are now considering, the individuals who have not internalized the majority code would not be inclined to take part in this horrific practice either. Presumably there is nothing in their human nature that would make them do so.

As a consequence, the non-rejectable code would not include any principles that govern what we ought to do in our actual world when we face other cultures that practice female genital mutilation. This means that the nonrejectable code would not, for example, require us to confront those who take part in this clearly immoral practice. Such additional requirement would not have any consequences in the compared worlds because these worlds only include a uniform majority culture and people who act solely on the basis of their human nature. Hence, the human nature response to the counter-culture challenge fails too.

\subsection{The Expected Burdensomeness Response}

The next alternative is to compare moral codes with the $\mathrm{n} \%$ internalization rate with all possible counter-cultures and their combinations. Not only should we compare the moral codes in worlds in which the code-rejectors are Lazies, but we should also compare these codes in worlds populated by Crazies, anarchists, paedophiles, psychopaths, Mafiosos, religious fundamentalist, and every possible combination of these and other possible counter-cultures. We would thus need to consider what consequences different moral codes have in the uncountably many different worlds in which the coderejectors have accepted different counter-cultures. How could we then decide which moral code is not reasonably rejectable?

Answering this question is easy for the ruleconsequentialists. They can calculate how much expected value different moral codes have in this vast set of 
possible worlds with different counter-cultures. ${ }^{12}$ Ruleconsequentialists can consider the consequences of a given moral code being internalized by $\mathrm{n} \%$ of people in a world populated by a certain counter-culture as one outcome. They can then add together the value this outcome contains - call this sum in the world $x$ " $\mathrm{V}_{\mathrm{x}}$ ". Let $\mathrm{s}$ be the number of different worlds with different countercultures. The expected value of a given moral code would thus be $\left[(1 / s)^{*} \mathrm{~V}_{1}\right]+\left[(1 / s)^{*} \mathrm{~V}_{2}\right]+\ldots+\left[(1 / s)^{*} \mathrm{~V}_{\mathrm{s}}\right]$. Ruleconsequentialists would then claim that an action is right if and only if it is authorized by the moral code that maximizes the amount of expected value in the comparisons of different codes at $n \%$ level of social acceptance in the set of worlds with different countercultures.

Contractualists will not be able to give this same answer to the previous question because it requires interpersonally aggregating the value of the consequences which each code and counter-culture pair has for different individuals. Contractualists do, however, have three other alternatives. For the sake of simplicity, let us compare just two moral codes $\mathrm{A}$ and $\mathrm{B}$ at $\mathrm{n} \%$ level of internalization. Imagine also that $\mathrm{p}, \mathrm{q}$, and $\mathrm{r}$ are the only possible countercultures which the code-rejectors could adopt. As a result, each moral code and counter-culture pair [A, p], [A, q], [A, $\mathrm{r}],[\mathrm{B}, \mathrm{p}],[\mathrm{B}, \mathrm{q}]$ and $[\mathrm{B}, \mathrm{r}]$ will create different kind of lives for the individuals in the compared worlds.

The first alternative is that we first find the most burdensome life from the three worlds $[A, p],[A, q]$, and $[A, r]$ and the most burdensome life from the world $[B, p]$, $[B, q]$, and $[B, r]$. We then compare which one of these two lives is more burdensome. If it is one of the A world lives, then the code A can be reasonably rejected and B cannot be. This is because no one needs to experience as burdensome life in any of the B worlds as someone has to experience in one of the A worlds.

\footnotetext{
12 This is an application of the basic insight of Ridge's variable rateutilitarianism to the counter-cultures instead of the levels of social acceptance (Ridge 2006 and 2009: sec. 5).
} 
This solution fails for a simple reason. A code can produce very good lives for everyone with all but one counterculture with which it produces a very burdensome life for just one individual. Thus, it could well be that this code has truly horrible consequences for the life of only one individual only if a very bizarre counter-culture is internalized by the 100-n\% minority. The current proposal would entail that this code could still be reasonably rejected by that one individual. This is unacceptable. The individual in question would have no reason to reject the considered code because with almost all counter-cultures that code has excellent consequences even for her.

The second alternative is to consider the 'expected maximum burdensomeness' of the different codes (EMB). ${ }^{13}$ According to this proposal, when we consider code $\mathrm{A}$, we first locate the most burdensome individual life from the pairs $[\mathrm{A}, \mathrm{p}],[\mathrm{A}, \mathrm{q}]$, and $[\mathrm{A}, \mathrm{r}]$. We then multiply the burdensomeness of these individual lives with the probability of the relevant counter-cultures (if each counter-culture is equally probable, by $1 / 3$ in my example) and we finally add these products together.

The problem with this solution is that it is difficult to connect it to a plausible contractualist account of the nature and role of reasonable rejectability. One fundamental contractualist insight is that we have reasons not to act wrongly because wrongful actions cannot be justified to each and every other individual (Scanlon 1998: 153-158; Parfit 2003: 371-374). ${ }^{14}$ Contractualists then claim that what can be justified to each and every individual is determined by which moral code individuals could not reasonably reject on the basis of the consequences which alternative moral codes have for them as individuals (Scanlon 1998: 229 - 241; Parfit 2003; Ridge 2001). If contractualists give up this personal criterion of

\footnotetext{
${ }^{13}$ I thank Campbell Brown for the distinction between EMB and MEB.

${ }^{14}$ Being able to justify your actions to each and every other person is then argued to constitute a valuable relationship of "mutual recognition" towards other people and the value of this relationship is then claimed to explain the reasons we have for avoiding wrongdoing.
} 
reasonable rejectability, it seems like they will need to give up their story of why we should not act wrongly.

Under EMB, the moral code A could be reasonably rejected as a consequence of a combination of what happens to Peter in the [A, p] world, to Quintin in the [A, q] world, and to Rita in the [A, r] world. Such a combined burden experienced by different individuals has very little to do with what can be justified to Peter, Quintin, or Rita as individual persons. For each one of them as individuals, A can be a good code except in the context of just one counter-culture. For this reason, it does not look like contractualists could coherently accept this response. Giving this response requires bringing back through the back-door interpersonal aggregations of burdens which contractualists insist on avoiding.

The third alternative is to compare the 'maximum expected burdensomeness' (MEB) of moral codes in the current framework. According to MEB, for each individual and a moral code, we consider how burdensome that particular code would be for that particular individual in the context of each potential counter-culture. Thus, in the case Peter and the code A in the previous example, we consider how burdensome Peter's life is in the worlds [A, p], [A, q], and [A, r]. We then first multiply the burdensomeness of Peter's life in each of these scenarios by the likelihood of those scenarios (by $1 / 3$ in this example assuming that all the countercultures are equally likely) and we then form a sum of these products. This process does not require any interpersonal aggregation. It only requires intrapersonal aggregation of burdens for individual persons, which contractualists accept more generally (Scanlon 1998: 237). For each code, we then identify the person for whom that code has the highest expected burdensomeness calculated in the way just explained. If the code A produces a higher expected burdensomeness for some individual than $B$ does for anyone, then A can be reasonably rejected and B cannot be.

This proposal could probably be connected to a plausible contractualist account of reasonable rejectability. This is because according to it only particular individuals can 
reasonably reject a moral code as a consequence of what the code does to them personally in different environments. Despite this, this response faces three serious challenges.

Firstly, this response suffers from an awkward technical problem. When we calculate the expected burdensomeness of a code for an individual we have to take into account how probable different counter-cultures are. We can either think that all counter-cultures and their combinations are equally likely or that some are likelier than others. The problem with the first alternative is that there are uncountably many different possible and bizarre counter-cultures which no one has internalized in the real world. If we let each one of these counter-cultures to have an equal influence on which moral code could not be reasonably rejected, then the non-rejectable moral code could include very strange moral requirements that would also apply to us in the real world. This is why it seems like a bad idea to consider each counter-culture to be equally likely in the contractualist comparisons.

This means that we should consider some of the possible counter-cultures to be more likely than others. What could such likelihoods represent? The only non-arbitrary way to answer this question is to claim that the likelihood in question stands for how likely it is that the relevant counter-cultures would be internalized in the actual world by those who do not accept the conventional morality.

This leads to the second problem of the current proposal. This proposal is threating to become too demanding epistemically. The current proposal is that an action is right if and only if it is authorized by the moral code which could not be reasonably rejected because it minimizes the maximum personal burdensomeness expectation. In order to know that an action is right in this framework, we would first need to know what consequences every possible moral code would have for the lives of individuals at $n \%$ level of internalization in uncountably many worlds in which the different counterculture have been internalized by the code-rejectors. This means that we would need to know how each possible moral code interacts with even the most bizarre counter- 
cultures. We would also need to know how likely it is that each one of these counter-cultures would be accepted in the actual world by those who do not accept the conventional morality. All this information would be difficult to come by.

Finally, there are also worries about how comfortably the current proposal actually fits the contractualist accounts of reasonable rejectability. Recall that contractualists are motivated by the moral ideal that we should be able to justify our actions to each and every individual. Consider then James who demands that you to justify to him the way you have treated him in some concrete situation. According to the current proposal, the justification which you should give to James is a function of what consequences moral codes have for different individuals in a vast number of worlds populated by code-rejectors who accept different counter-cultures - some of which are very alien from the perspective of the real world. It is less clear just how these considerations could satisfy James's legitimate demand that you should be able to justify your actions to him on grounds he could not reasonably reject. The current response to the counter-culture challenge thus seems too far removed from the original contractualist moral ideal of justification.

We can therefore conclude that the different responses to the counter-culture challenge that rely on the idea of expected burdensomeness are problematic. They face awkward theoretical questions about probabilities, they have implausible normative consequences, they are epistemically demanding, and they fail to fit the contractualist account of justifiability to each and every person.

\subsection{Real World Contractualism}

Finally, I want to introduce a response to the counterculture challenge, which I believe is more plausible than the previous alternatives. I will first introduce this proposal and then explain why it can avoid the main problems of the previous three responses.

By definition, "conventional morality" is the moral code which in fact has been internalized by the majority of 
people at the moment in the actual world. Given that we are using the notion of a moral code to stand for a complex moral sensitivity (footnote 1) and there are always small differences between different people's moral sensitivities, it is admittedly somewhat vague just which moral beliefs, cares and concerns, values, emotions, behavioural and motivational dispositions, and patterns of reactive attitudes you need to have in order to count as someone who accepts the conventional morality. Despite this, there inevitably is (i) a majority of people in the actual world who has definitely internalized the conventional morality, (ii) a minority who definitely hasn't done so, and (iii) borderline cases of people who do not determinately belong to either (i) or (ii).

Let us then consider all the actual people who have definitely not internalized the conventional morality. ${ }^{15}$ The members of this group have internalized different counter-cultures. We can, for example, find psychopaths, paedophiles, extreme egoists, anarchists, and religious fundamentalists from this group. It is also possible to empirically investigate what percentage of this group accepts a given counter-culture. This means that $\mathrm{x} \%$ of the actual people who have not internalized the conventional morality are psychopaths, $\mathrm{y} \%$ are anarchists, $\mathrm{z} \%$ are religious fundamentalists, and so on. There is then a certain proportion of this actual group of code-rejectors that accepts each actual counter-culture.

Real World Contractualism uses these facts to construct a response to the counter-culture challenge. We are comparing different moral codes in worlds in which $\mathrm{n} \%$ of people have internalized the compared codes. The idea then is that the rest of the population in these worlds have accepted exactly the same counter-cultures as the people who have not internalized the conventional morality in the actual world. Furthermore, these counter-cultures are

\footnotetext{
${ }^{15}$ What about the people who neither determinately belong to this category nor to the category of people who have not internalized the conventional morality? We can either include all, some or none of them to the considered people. Whichever choice we make here, will not have much of an impact given that these individuals are very close to accepting the conventional morality.
} 
accepted in the same proportion as the counter-cultures are accepted in the actual world by the actual coderejectors. This means that if $\mathrm{x} \%$ of the people who have not internalized the conventional morality in the actual world are paedophiles, then the same $x \%$ of the people who belong to the $100-\mathrm{n} \%$ minority in the compared worlds are paedophiles, and similarly for all other countercultures we can find from the actual world. Thus, we get exactly the same counter-cultures in the compared worlds as we have in the actual world, and we get these counter-cultures in the same proportions as we find them from the actual world. ${ }^{16}$

Let us then explore how this proposal avoids the problems of the previous proposals. Firstly, in response to Smith's original counter-culture challenge, it is clear that we have not chosen the counter-cultures for the contractualist comparisons of moral codes arbitrarily. To see this, let us consider natural resources. Just like we can compare moral codes in the context of different counter-cultures, we could also compare these codes in worlds that have very few natural resources and in ones that are incredibly rich with resources. Despite this, contractualists compare moral codes only in worlds that have the same amount of natural resources as our world.

Why exactly is this justified and not arbitrary? Presumably the thinking behind comparing codes only in worlds that have the same resources as our world is that we want the contractualist framework to generate moral principles that

\footnotetext{
${ }^{16}$ One interesting consequence of Real World Contractualism is that it makes what is right and wrong to a degree relative to time and perhaps even place given that different times and places in the actual world can have different actual counter-cultures. This view, thus, really makes for example the rightness and wrongness of carrying, buying, and selling fire-arms relative to the time and place. After all, whether the principles that would govern the availability of fire-arms can be reasonably rejected turn out to depend on what the actual members of the counter-cultures would do with the fire-arms. This can, of course, change in the actual world depending on time and place. I believe that this form of relativism and context-dependency will not be objectionable at least in any obvious way. It also nicely fits Scanlon's own "parametric universalism", which he defended in the often ignored chapter on relativism in What We Owe to Each Other (Scanlon 1998: ch. 8).
} 
are relevant and applicable in the real world situations we face (Rawls 1971: 126-130). This is why it is not arbitrary to compare moral codes only in worlds that have the same amount of natural resources as our world.

Real World Contractualism follows this same line of thought. It claims that we should compare moral codes in worlds that are populated by individuals who accept the genuine counter-cultures of the actual world. This is the only way to guarantee that the contractualist framework will generate moral principles that are relevant and applicable in our actual circumstances. If the decision to compare moral codes in the context of the actual amount of natural resources then is not arbitrary for this reason, then comparing these codes only in the context of actual counter-cultures should not be arbitrary either. In fact, we can treat the counter-cultures in the comparisons of moral codes very much like natural resources.

Secondly, this proposal can avoid the redundancy objection, which was fatal for the reflective equilibrium response. Real World Contractualism does not rely on pretheoretical moral convictions in choosing which countercultures are used in the relevant comparisons of moral codes. The unique combination of counter-cultures is used solely because we find it from the actual world. This is why Real World Contractualism can offer a critical perspective for both evaluating and vindicating our moral convictions, and why it can also play a role in explaining what is right and wrong and why. It can turn out that the moral code which is the least burdensome according to Real World Contractualism is in important respects different from our conventional morality. It can then be argued that following our moral convictions is burdening some individuals unnecessarily and for this reason we should correct our convictions to match the moral principles picked out by Real World Contractualism.

Thirdly, my proposal does not make any claims about the human nature. If there is one, then we can expect that it is reflected in the actual counter-cultures. For this reason, Real World Contractualism is compatible with the idea that the behaviour of the code-rejectors in the compared worlds is at least in part determined by their human 
nature. However, if we also find counter-cultures from the actual world that are not biologically determined, then Real World Contractualism will also take these countercultures into account in the contractualist comparisons of moral codes. This is why the case of female genital mutilation will not be a problem for this proposal.

Fourthly, Real World Contractualism will not require aggregating burdens of different individuals interpersonally in the comparisons of the moral codes. Only personal objections which concrete individuals can make to the moral code they live under in the described circumstances are taken into account.

This idea leads to the fifth advantage of the proposal: it fits the standard contractualist accounts of reasonable rejectability. As explained, contractualists try to make sense of what can be justified to each and every individual person in terms of the principles which no individual could reasonably reject. The moral code picked out by Real World Contractualism fits this account. The general acceptance of any other code than the non-rejectable code would lead to more serious personal burdens for some individuals in the worlds that are populated by countercultures exactly like the ones we find in the actual world. This is what you can say to James when he asks you to justify to him the way you have treated him. You can argue that the moral codes that would forbid you to act in the way that you did would all cause unnecessary burdens to some individuals in circumstances which are exactly like the ones we are in. This is something James should be concerned about as far as he grants other actual people an equal moral status.

Finally, my proposal is less demanding epistemically than the expected burdensomeness responses. There will be no need to attempt to find out how likely the internalization of different counter-cultures is in the actual world. We also do not need to know what consequences different moral codes would have in bizarre counter-culture worlds. All we need to know is what kind of consequences different moral codes have in circumstances in which the code-rejectors are exactly like the people who don't accept the conventional morality in the actual world. 
We should not underestimate how difficult even this information is to acquire, but at least this is far less information than what is required by the expected burdensomeness responses. For one, we can already observe in the actual world what kind of consequences different conventional moral codes have for the lives of individuals in the circumstances in which the coderejectors accept the actual counter-cultures. This is why Real World Contractualism is epistemically less demanding than the expected burdensomeness responses that all require much more information about how different moral codes and counter-cultures interact.

\section{Conclusion}

If the previous arguments are along the right lines, then Real World Contractualism is the best available contractualist response to the counter-culture challenge because it can avoid the problems of the other alternatives. As a consequence, there is a well-defined and wellmotivated contractualist procedure for selecting which moral code could not be reasonably rejected. This means that an ethical theory based on such a code is still a serious candidate when we consider which ethical theory best captures which actions are right and wrong and why. Whether contractualism can ultimately be vindicated as the correct ethical theory will then depend on its other advantages and problems (see footnote 5) and on how they compare to the advantages and problems of other ethical theories. Here my aim was merely to provide a satisfactory response to the counter-culture challenge.

\section{Bibliography}

Alexander, Richard (1987): The Biology of Moral Systems (New York: de Gruyter).

Ashford, Elizabeth (2003): "The Demandingness of Scanlon's Contractualism". Ethics 113: 273-302.

Bittner, Rüdiger (1974): “Maximen”. In G. Funke (ed.): Akten des 4. Internationalen Kant-Kongresses (Berlin: de Gruyter), vol. II. 2., 485-498.

Blackburn, Simon (1999): “Am I Right?” New York Times, February 21. 
Brandt, Richard (1959): Ethical Theory (Englewood Cliffs, NJ: Prentice-Hall).

Brandt, Richard (1967): "Some Merits of One Form of Rule-Consequentialism". University of Colorado Studies in Philosophy 3: 39-65.

Brandt, Richard (1979): A Theory of the Good and the Right ( Oxford: Clarendon Press).

Brandt, Richard (1992): Morality, Utilitarianism, and Rights (New York: Cambridge University Press).

Carruthers, Peter (1992): The Animal Issues: Moral Theory in Practice (Cambridge: Cambridge University Press).

Daniels, Norman (1979): “Wide Reflective Equilibrium and Theory Acceptance in Ethics". The Journal of Philosophy 76: 256-282.

Dawkins, Richard (1976): The Selfish Gene (Oxford: Oxford University Press).

De Lazari-Radek, Katarina \& Singer, Peter (2014): From the Point of View of the Universe - Sidgwick \& Contemporary Ethics (Oxford: Oxford University Press).

Frankena, William (1973): Ethics, 2nd ed. (Englewood Cliffs, NJ: Prentice-Hall).

Hare, R.M (1973): "Rawls's Theory of Justice". The Philosophical Quarterly 23: 144-155 and 241-251.

Hirose, Iwao (2001): "Saving the Greater Number without Combining Claims". Analysis 61: $341-342$.

Hooker, Brad (2000): Ideal Code, Real World (Oxford: Oxford University Press).

Hooker, Brad (2003): "Scanlon's Contractualism, the Spare Wheel Objection, and Aggregation". In M. Matravers (ed.): Scanlon and Contractualism (London: Frank Cass): 53-76.

Hooker, Brad and Fletcher, Guy: "Variable versus FixedRate Rule-Utilitarianism". The Philosophical Quarterly 58: 344-352

James, Scott (2011): An Introduction to Evolutionary Ethics (Oxford: Wiley-Blackwell).

Kumar, Rahul (2000): "Defending the Moral Moderate". Philosophy and Public Affairs 28: 275-309

Kumar, Rahul (2001): "Contractualism on Saving Many". Analysis 61: 165-170. 
Kymlicka, Will (1991): “The Social Contract Tradition". In P. Singer (ed.): A Companion to Ethics (Oxford: Blackwell), 186-196.

Norcross, Alastair (2002): “Contractualism and Aggregation". Social Theory and Practice 28: 303-314.

Otsuka, Michael (2000): "Claims of the Many versus the One". Analysis 60: 288-293.

Parfit, Derek (2003): "Justifiability to Each Person". Ratio 16: 368-390.

Parfit, Derek (2011): On What Matters, Vols. 1-2 (Oxford: Oxford University Press).

Pettit, Philip (2000): “Two Construals of Scanlon's Contractualism". The Journal of Philosophy 96: 148164.

Phillips, David (1998): "Contractualism and Moral Status". Social Theory and Practice 24: 184-204.

Reibetanz, Sophie (1998): "Contractualism and Aggregation". Ethics 108: 346-367.

Rawls, John (1971): A Theory of Justice (Cambridge, MA: Harvard University Press).

Raz, Joseph (2003): "Numbers, with and without Contractualism". Ratio 16: 346-367.

Regan, Donald (1980): Utilitarianism and Co-Operation (Oxford: Oxford University Press).

Ridge, Michael (2001): "Saving Scanlon: Contractualism and Agent-Relativity". The Journal of Political Philosophy 9: 472-481.

Ridge, Michael (2006): "How to be a Rule-Utilitarian: Introducing Variable Rate Rule-Utilitarianism". The Philosophical Quarterly 56: 242-253.

Ridge, Michael (2009): “Climb Every Mountain?” Ratio 22: 59-77.

Scanlon, T.M. (1998): What We Owe to Each Other (Cambridge, MA: Harvard University Press).

Scanlon, T.M. (2000): "A Contractualist Reply". Theoria 66: 237-245.

Scanlon, T.M. (2002a): "Replies". Social Theory and Practice 28: 337-358.

Scanlon, T.M. (2002b): "Reasons, Responsibility and Reliance". Ethics 112: 507-528.

Scanlon, T.M. (2003a): "Reply to Gauthier and Gibbard". Philosophy and Phenomenological Research 66: 176189. 
Scanlon, T.M. (2003b): “Replies”. Ratio 16: 424-439.

Smith, Holly (2010): "Measuring the Consequences of Rules". Utilitas 22: 413-433.

Sober, Elliot \& Sloan Wilson, David (1998): Unto Others the Evolution and Psychology of Unselfish Behaviour (Cambridge, MA: Harvard University Press).

Southwood, Nicholas (2003): "Moral Contractualism". Philosophy Compass 4/6: 926-937.

Southwood, Nicholas (2010): Contractualism $\mathcal{E}$ the Foundations of Morality (Oxford: Oxford University Press).

Stratton-Lake, Philip (2003): “Scanlon's Contractualism and Redundancy Objection," Analysis 63: 70-76.

Suikkanen, Jussi (2004): "What We Owe to Many". Social Theory and Practice 30: 485-506.

Suikkanen, Jussi (2005): "Contractualist Responses to the Redundancy Objections". Theoria 71: 38-58.

Suikkanen, Jussi (2014): "Contractualism and the Conditional Fallacy". Oxford Studies in Normative Ethics 4: 113-137.

Thomson, Judith Jarvis (1990): The Realm of Rights (Cambridge, MA: Harvard University Press).

Van Parijs, Philippe (1991): “Why Surfers Should be Fed: The Liberal Case for an Unconditional Basic Income". Philosophy and Public Affairs 20: 101-131. 